EMBRYARIDDLE
Aeronautical University

SCHOLARLY COMMONS

\section{International Journal of Aviation,} Aeronautics, and Aerospace

\title{
Simulation Analysis of the Effects of Performance-Based Navigation on Fuel and Block Time Efficiency
}

Shlok Misra

Embry-Riddle Aeronautical University, Daytona Beach, misras@my.erau.edu

Follow this and additional works at: https://commons.erau.edu/ijaaa

Part of the Aviation Safety and Security Commons, and the Management and Operations Commons

\section{Scholarly Commons Citation}

Misra, S. (2020). Simulation Analysis of the Effects of Performance-Based Navigation on Fuel and Block Time Efficiency. International Journal of Aviation, Aeronautics, and Aerospace, 7(4). https://doi.org/ 10.15394/ijaaa.2020.1528

This Article is brought to you for free and open access by the Journals at Scholarly Commons. It has been accepted for inclusion in International Journal of Aviation, Aeronautics, and Aerospace by an authorized administrator of Scholarly Commons. For more information, please contact commons@erau.edu. 
Commercial aviation has seen a steady rise over the past decade (20102019) in the United States of America (US) in terms of the number of flights operated and passengers traveled. According to statistics reported by the Department of Transportation (DOT) through the Bureau of Transportation Statistics (BTS), the number of flights operated in the US has seen a $2.2 \%$ rise from 2010 to 2019, and the number of passengers traveled has seen a rise of $33.68 \%$ in the same period (DOT, 2020). An increase in the number of flights operated in the National Airspace System (NAS) leads to system delays which ultimately leads to increased costs for the operators/airlines and an increase in fuel emissions (FAA, 2018). The delay costs to the airlines include direct compensation to passengers for missed flights or connections and reputation costs (Ferguson et al., 2013). State agencies such as the Federal Aviation Administration (FAA), airlines, and stakeholders in the NAS have directed efforts towards improving the efficiency of the NAS while maintaining the safety standards. Some of these efforts include developing Performance-based Navigation (PBN), Performance-based Communication and Surveillance (PBCS), Automatic-Dependent SurveillanceBroadcast (ADS-B), and Collaborative Decision Making (CDM)(FAA, 2018).

The FAA NextGen Program is a major effort by the FAA to develop technologies to prepare the NAS for the growing air traffic demand (FAA, 2018). While the NextGen program is being developed and implemented on an industrywide level with the FAA, airlines have taken initiatives as well to improve operational efficiencies such as improving cost index calculation algorithms and investing in disruption management strategies and technology (Maria et al., 2017). Increasing efficiency and reducing costs while maintaining safety has been a major goal for the airlines and the FAA while introducing new strategies and initiatives.

\section{Statement of the Problem}

The NextGen Program is aimed towards modernizing the NAS by introducing technology that will not only improve efficiency but also reduce operating costs and improve environmental considerations such as reducing fuel emissions (FAA, 2018). The implementation of PBN is a global effort to shift the dependency for navigation from ground-based systems to satellite-based systems (Kasim, 2017). PBN is changing the way aircraft navigate through the NAS (Kasim, 2017). The FAA claims that the implementation of PBN will allow operators to fly more efficient routes and improve the efficiency of departure and arrival routing through Optimized Descent Paths (OPDs) (FAA, 2016b). As of 2020, the FAA is midway through the implementation of the NextGen program that has been planned to be implemented in four segments between 2010 and 2030 (FAA, 2018). The four segments are Alpha (2010-2015), Bravo (20162020), Charlie (2020-2025), and Delta (2026-2030) (FAA, 2018). As of 2020, the FAA is transitioning from the Bravo segment to the Charlie segment and is 
approximately at the mid-point of the 20 years long implementation period. However, there is a lack of literature that quantifies the benefits of utilizing PBN on flights of different distances and times. Considering that 2020 is a transition stage and a mid-point of the implementation plan, there is a need for a quantitative assessment of the progress made by the FAA and the benefits it currently offers to operators and airlines operating in the NAS.

The purpose of this study was to analyze the effects of PBN on fuel and block time efficiency. Additionally, the study assessed the benefits of utilizing PBN for flights of varying flight times and distances. This study is a quantitative assessment of the benefits of PBN offered for flights of varying distances and flight times.

PBN will impact all stakeholders of the NAS as it will change the way flights navigate and operate through the NAS (FAA, 2016b). The study is significant for airline operators and stakeholders in the NAS. Considering that 2020 is a transition stage from the Bravo segment to the Charlie segment of the NextGen implementation plan and it's approximately the mid-point of the 20 years long implementation plan, this study offers a quantitative assessment of the benefits of PBN for operators and airlines that utilize the PBN infrastructure in the NAS. With the completion of the PBN implementation scheduled in 10 years (2030), the results of this study will also benefit stakeholders and airlines in forecasting and predicting the future impact of PBN on flight operations. The results of this study can be used to assess operational strategies such as variations in cost index calculations for routes and developing investment strategies for utilizing PBN for flight operations on different routes. The results of this study can be utilized for further research on optimization models and methods for calculating block times.

\section{Research Questions}

The researcher for this study conducted the study to answer the following research question:

- How does fuel and block time efficiency change when using PBN routes and procedures for flights of different distances?

\section{Review of Relevant Literature}

\section{FAA NextGen Program}

The FAA NextGen program aims to modernize the NAS while maintaining the safety standards of the NAS. The FAA describes the NextGen program as "the planning and implementation of innovative new technologies and airspace procedures after thorough safety testing" (FAA, 2020b, p. 1).

The FAA explains that replacing legacy systems with digital technology is a core element of the NextGen program (FAA, 2020b). This shift leads towards better cost-saving techniques, better environmental considerations, and improved 
efficiency and performance. The NextGen program is aimed towards modernizing three critical areas of the NAS which are communication, navigation, and surveillance. In the communications focus, the FAA has focused on increasing the reliance on datalink methods of communication between the aircraft and Air Traffic Control (ATC). The increased use of datalink results in a faster, more reliable, and more accurate exchange of messages between ATC and pilots. Some programs that are being implemented in the NextGen program that focus on communication are Controller Pilot Datalink Communications (CPDLC), ADS-B, and Automatic Database Broadcast-Contract (ADS-C). In the navigation focus, the FAA has focused on increasing the reliance on satellite-based equipment and procedures and moving away from the reliance and usage of ground-based equipment such as Very High-Frequency Omnidirectional Range (VORs) and Instrument Landing System (ILS). Satellite-based systems are more reliable and allow aircraft to fly more precise and efficient routes along with more efficient climbs and descents into and out of airports. Satellite-based navigation will not only improve the efficiency of the NAS but also help operators cut costs on fuel and reduce delays as aircraft will fly more direct routes. In the surveillance focus, the FAA is focused on improving the accuracy and performance of surveillance systems that are used by ATC. Some of the key programs that are the focus in the NextGen program are Data Communication (Data Comm), PBN, ADS-B, Decision Support System (DSS), System Wide Information Management (SWIM), and other environmental and safety initiatives. The analysis in this study was limited to the usage of PBN.

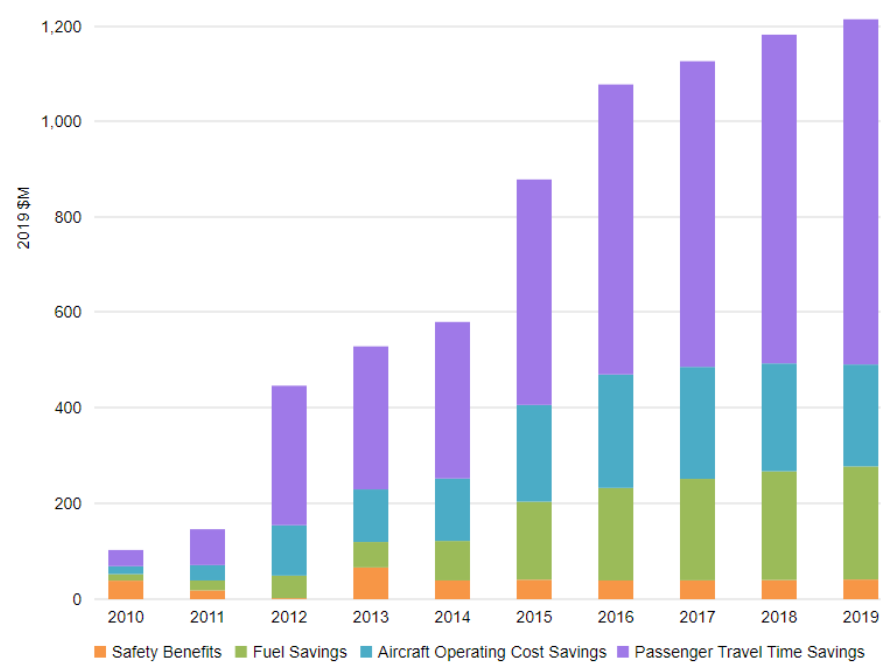

Figure 1. Benefits (estimated in US Dollars) achieved per year through the NextGen program (FAA, 2020c). 
As depicted in Figure 1, the FAA estimates that the NextGen program has accrued approximately \$7 Billion in benefits from 2010 to 2019 (FAA, 2020c). The FAA estimates that these benefits have been achieved in areas such as safety, fuel savings, aircraft operating costs, and passenger travel times.

\section{Performance-Based Navigation}

Performance-based Navigation (PBN) is a global effort to increase the reliance for navigation on satellite-based equipment from ground-based navigation. $\mathrm{PBN}$ is being led by state aviation agencies all around the world and the FAA in the US. The International Civil Aviation Organization (ICAO) published the PBN Manual Doc 9613 in 2008 that provides guidance for state agencies around the world to develop PBN procedures. The manual can be used as a framework for designing and implementing PBN around the world.

PBN allows aircraft to fly more direct routes to their destination which lowers fuel burn and travel times (Eagan \& Gundry, 2018). PBN is beneficial for the NAS as it allows for lower delays and more efficient routing of aircraft leading to lower congestions (Eagan \& Gundry, 2018). PBN also benefits the environment with higher availability of more efficient routing with optimized descents/climbs in and out of terminal airspaces which lower fuel emissions. PBN procedures enhance safety due to increased accuracy and reliability of navigational equipment (Tian et al., 2015).

PBN moves from navigation services provided based on equipment available on the aircraft to navigational services provided based on the performance limitations of navigational equipment of an aircraft. The introduction of PBN has led to a systematic assessment of the performance capabilities and limitations of navigational equipment available in an aircraft. This assessment was used to standardize codes and associated privileges/services available for different performance levels. This precise metering of the performance capabilities and limitations has allowed a more efficient infrastructure that allows aircraft equipped with higher performance level equipment to leverage the benefits of the PBN infrastructure. This results in aircraft operating through more precise and efficient procedures and routes during a flight (Nakamara \& Royce, 2008). Aircraft operators are now incentivized to equip aircraft with more advanced equipment to avail services that could reduce operating costs and flight time. Aircraft equipment is now categorized and assigned codes that designate the performance limitations of the aircraft (in terms of navigation) that are included in the flight plan form submitted to Air Traffic Control (Nakamura \& Royce, 2008).

PBN consists of two major specifications: Area Navigation (RNAV) and Required Navigation Performance (RNP) (Nakamura \& Royce, 2008). RNAV allows aircraft to fly more direct routes due to the ability of pilots to navigate using satellite-based Global Position System (GPS) equipment. Aircraft equipped with RNAV equipment have access to point-to-point navigation that provides 
efficiency and flexibility. RNAV increases system capacity and reduces delays and congestions. RNAV allows pilots to navigate through either pre-defined GPS waypoints or fixes located by latitudes and longitudes. Different aircraft equipment have varying navigation capabilities that differentiate the types of PBN routes and procedures that can be flown by aircraft. RNAV designators such as RNAV 1, RNAV 2, and RNAV 10 categorize the navigational RNAV capabilities of the aircraft. The FAA has published guidance for operators for the RNAV codes for different equipment that must be included in the filed flight plan (FAA, 2020a). Required Navigational Performance (RNP) adds on RNAV with additional functional enhancements related to accuracy and integrity monitoring (Nakamura \& Royce, 2008). RNP is characterized by onboard performance monitoring and alerting capability which improves the integrity of the aircraft's navigational capabilities. A higher RNP category helps the aircraft fly highly precise routes, especially in the approach phase. These precise routes help the aircraft reduce fuel burn and also helps the NAS with noise abatement procedures. The FAA has published Advisory Circular 90-105A regarding the certification and implementation of PBN equipment for US civil aircraft (FAA, 2016a). The aircraft's navigation equipment is designated RNP values which denote the aircraft navigational integrity and performance monitoring capability. The FAA explains that the RNP value "designates the 95 percent lateral navigation (LNAV) performance (in NM) and the related monitoring and alerting requirements associated with an RNP instrument flight operation or a particular segment of that instrument flight" (FAA, 2016, p. 4-2). The RNP values are designated in terms of nautical miles where an RNP0.3 value denotes that an aircraft can maintain a tracking accuracy of $+/-0.3 \mathrm{NM}$ for $95 \%$ of the flight (FAA, 2016a). As illustrated in figure 2, the lower the RNP value, the higher the accuracy and integrity monitoring capabilities.

\begin{tabular}{|c|c|c|c|c|c|c|c|c|}
\hline & \multicolumn{7}{|c|}{ Flight Phase } \\
& \multicolumn{9}{|c|}{ Approach } & Terminal \\
\hline \multirow{2}{*}{$\begin{array}{c}\text { Navigation } \\
\text { Specifications }\end{array}$} & $\begin{array}{c}\text { En route } \\
\text { Oceanic/Remote } \\
\text { Continental }\end{array}$ & $\begin{array}{c}\text { En route } \\
\text { Domestic }\end{array}$ & Arrival & Initial & Intermediate & Final & Missed & Departure \\
\hline$\underline{\text { RNP 1 }}$ & N/A & N/A & 1 & 1 & 1 & N/A & 1 & 1 \\
\hline$\underline{\text { RNP 2 }}$ & 2 & 2 & N/A & N/A & N/A & N/A & N/A & N/A \\
\hline$\underline{\text { RNP 4 }}$ & 4 & N/A & N/A & N/A & N/A & N/A & N/A & N/A \\
\hline$\underline{\text { RNP 10 }}$ & 10 & N/A & N/A & N/A & N/A & N/A & N/A & N/A \\
\hline$\underline{\text { A-RNP }}$ & 2 & 2 or 1 & $1-0.3$ & $1-0.3$ & $1-0.3$ & N/A & $0.3-1$ & $0.3-1$ \\
\hline$\underline{\text { RNP APCH }}$ & N/A & N/A & N/A & 1 & 1 & 0.3 & 1 & N/A \\
\hline$\underline{\text { RNP 0.3 }}$ & N/A & 0.3 & 0.3 & 0.3 & 0.3 & N/A & 0.3 & 0.3 \\
\hline
\end{tabular}

Figure 2. RNP Values and integrity and monitoring performance for flight phases (FAA, 2016a). 
PBN implementation is a major focus of the FAA NextGen program. The FAA published updates on the implementation of PBN in the FAA NextGen Implementation Plan 2018-2019 (FAA, 2018). The implementation of PBN will be completed by the end of the Delta segment of the NextGen program (FAA, 2018). The FAA is currently (as of August 2020) moving towards equipping more airports with RNAV and RNP procedures and increasing the usage and availability of high-performance navigational procedures such as RNP-AR (Required Navigational Performance-Authorization Required) procedures.

The FAA selected 29 airports in the US and designated them as core airports for the implementation of PBN (FAA, 2020b). The 29 core airports have the highest focus on PBN and are the most advanced and well-equipped for PBN procedures. As of October 2017, the FAA had implemented OPDs at 20 core airports, RNP-AR procedures at 25 core airports, and RNAV procedures for 29 core airports and 310 non-core airports. For the purpose of the simulation in this study, all flights will depart and arrive at core airports to leverage the higher number of PBN procedures available at core airports.

\section{PBN Implications on Flight Planning}

Scheduled air carriers/airlines operate under the regulations mandated under 14 Code of Federal Regulations Part 121. Airlines also utilize companyspecific operations specifications for managing flight planning and operations. Larger transport category aircraft utilize flight altitudes above 18,000 feet which places these flights in Class A airspace. As detailed in the Aeronautical Information Manual Section 3-2-2, all flight operations conducted in Class A airspace are to be conducted under Instrument Flight Rules (IFR) (FAA, 2020a). IFR flight operations utilize pre-defined navigational procedures and routes that can be accessed by pilots from published high-altitude charts and terminal procedures publications. The implications of PBN can be studied for IFR flights in three separate segments which are departure, en-route, and arrival.

\section{Departure}

For this analysis, the departure segment of a flight is considered the segment of a flight when an aircraft takes-off from the departure airport and climbs to the cruise altitude. An aircraft is directed from the terminal airspace to the en route segment by ATC through radar vectors or published departure routes. As detailed in the Aeronautical Information Manual Section 5-2-9, published departure procedures can be either Obstacle Departure Procedures (ODPs), Standard Instrument Departures (SIDs), or Departure Vector Areas (DVAs) (FAA, 2020a). The flight crew operating the flight will be cleared to utilize a published departure procedure to climb out of the terminal airspace. These published departure procedures utilize navigational facilities such as VORs, NDBs, or DME. However, with the introduction of PBN, the FAA is moving towards introducing RNAV GPS departure procedures which will allow aircraft to 
fly to the en route segment through more direct routes reducing fuel burn and time taken to reach the en route segment.

\section{En-route}

For the purpose of this analysis, the en-route segment of flight will be considered the segment of the flight when the aircraft reaches the cruise altitude to the point when the aircraft commences descent to the arrival airport. The en route segment of a flight under IFR is operated by either flying through predefined airways (Victor Airways below 18,000 feet and Jet Routes above 18,000 feet). Flights could also fly direct between waypoints subjected to ATC approval and operations. With the introduction of PBN, the FAA is moving towards increasing the availability of GPS routes (such as Q-routes and T-routes), which utilize GPS waypoints rather than ground-based equipment for creating waypoints. Increased availability of GPS routes helps reduce flight times and fuel burn as GPS routes offer more direct routing to aircraft as they are not dependent on the location of ground-based equipment (FAA, 2020a).

\section{Arrival}

For the purpose of this analysis, the arrival segment of a flight will be considered the segment of the flight when the aircraft begins the descent from the en route segment to the arrival airport. Aircraft utilize ATC instructions for descent and utilize predefined arrival procedures. As detailed in the Aeronautical Information Manual Section 5-4-1, published arrival procedures are called Standard Terminal Arrival Routes (STARs) (FAA, 2020a). STARs are predefined arrival routes that pilots utilize with the approval of the controlling ATC agency. STARs allow efficient sequencing of arriving aircraft to the airport and reduce pilot-controller workload. The FAA has invested significantly in improving the efficiency of STARs and instrument approach procedures utilized for aircraft arriving airport under IFR. The FAA aims to increase the availability of RNAV GPS and RNP arrival procedures that utilize higher GPS navigational standards than ground-based equipment. RNAV GPS and RNP procedures allow more precise routes into the airport reducing the total distance in the arrival segment, fuel burn, and flight time. Another advantage of implementing PBN in the arrival segment in the higher availability of OPDs, which allow a more fuelefficient arrival due to the reduction in step down level-offs for arriving aircraft. Aircraft that are equipped with higher performance navigational equipment can utilize RNAV GPS and RNP procedures which will help navigate the aircraft in less time, distance, and fuel burn.

\section{Block Time}

Airlines schedule flights with respect to block times. Sohoni et al. (2011) define block time of a flight as the time elapsed for a flight from push-back at the departure gate to arrival at the destination gate. In colloquial terms, block time is also referred to as the time from 'chocks off to chocks on' where chocks refer to 
the parking brake and chocks for the wheels placed when the aircraft is parked at the gate. The block time comprises of the taxi-out time, en route time, and taxi-in time (Sohoni et al., 2011). Block times are of high significance for airlines as an inaccurate prediction of block times can not only lead to delayed flights but also lead to inefficient scheduling of resources. The FAA maintains data on the OnTime Performance (OTP) of airlines, which is a common measure for assessing airline efficiency and performance. According to the Department of Transport (2020), a flight is 'on-time' if it arrives within 15 minutes after its scheduled arrival time. A flight is considered delayed if the flight arrives 15 minutes or more after its scheduled arrival time. Block times are a vital tool for airlines to estimate scheduled arrival times.

Literature suggests that significant progress has been achieved in optimizing block time calculations. Sohoni et al. (2011) suggest that inaccurate block time calculations do not only lead to system delays for the airlines but also affect network and schedule designs of airlines. Sohoni at. al (2011) designed a stochastic integer programming formulation that was aimed at optimizing and maximizing profits for an airline that included optimizing block time estimations. Fan (2019) studied the systematic change in scheduled block times for non-stop flights from 1986 to 2016. Fan observed that scheduled block times have been increasing by 0.21 minutes to 0.33 minutes every year for non-stop flights. Some of the factors that have led to this constant increase in block time are air traffic growth, airport-specific congestions, flight delays, and airport slot policy amongst other factors. An increase in block time leads to lesser flights being scheduled per aircraft in a given period of time.

Kang and Hansen (2018) explained that block times directly impact an airline's on-time performance and operating costs. Kang and Hansen studied the impact of airport surface congestion management programs on block times of airlines. Kang and Hansen developed a prediction model to predict the impact of airport surface congestion on block times of aircraft. The block time of a flight can be impacted by factors on the airport surface or in the air during the flight.

\section{Methodology}

The purpose of this study was to analyze the effects of PBN on fuel and block time efficiency. The researcher utilized a quantitative research method with a simulation design for the study.

\section{Data}

The data for this study was collected from 20 simulated flights. Out of the 20 flights, 10 of the flights were operated without using any GPS routes or RNP procedures (denoted as Group A), and the other 10 flights were operated utilizing GPS and RNP procedures (denoted as Group B). The flights were planned utilizing the Navblue Flight Planning software and the flights were simulated 
utilizing Aerowinx Flight Precision Simulator. The researcher selected 10 citypairs (One origin to one destination) and simulated one Group A flight and one Group B flight for each route. The origin and destination in each sector was a core airport in the PBN implementation plan as the researcher aimed to utilize the best PBN capabilities available in the NAS for credible data collection (FAA, 2020b).

\section{Group A flights}

The researcher planned the flights on the Navblue Flight Planning software by disabling GPS availability and utilizing the lowest PBN capability as per the guidance from the FAA. The most efficient route with the defined parameters was planned by Navblue.

\section{Group B flights}

The researcher planned the flights on the Navblue Flight Planning software by enabling GPS availability and the highest PBN capability as per the guidance of the FAA. The researcher planned the flights utilizing PBN to the highest extent and degree possible. Utilizing the highest extent implies that at certain route segments, the research planned the flight utilizing J-routes (utilizing ground-based equipment) or ground-based approach procedures when a comparable RNAV(GPS) route or procedure wasn't available. Utilizing PBN to the highest degree possible implies that the researcher utilized routes and procedures utilizing the highest RNAV performance category and RNP category available for each sector in the Navblue Flight Planning software. Additionally, the researcher utilized RNP-AR procedures when one was available. The researcher utilized PBN to the highest degree possible to gather credible data for analysis and comparison.

\section{Navblue Flight Planning}

The researcher utilized Navblue Flight Planning for planning the 20 simulated flights. Navblue Flight Planning is an operations solution offered by Airbus that specializes in providing applications for flight planning, crew management, performance planning, and fleet management (Navblue, 2020). Navblue allows operators and dispatchers to plan flights efficiently utilizing aircraft data and the worldwide navigation data that is available for Navblue users. The researcher utilized the Boeing 747-400 flight planning data that was incorporated in the Navblue Flight Planning software. The researcher planned 10 flights for Group A and 10 flights for Group B. The researcher was able to disable RNP and GPS (RNAV) procedures for the Group A flights and utilize RNP and GPS (RNAV) procedures to the highest extent and degree possible for Group B flights. The researcher was able to accomplish this through the 'user' and 'administrator' accounts available to the researcher that allowed the researcher to manipulate the aircraft navigational capability settings. 


\section{Aerowinx Precision Flight Simulator}

Aerowinx Precision Flight Simulator (Aerowinx) is a commercially available desktop flight simulator that is widely used for training and research purposes (Aerowinx, 2020). Aerowinx utilizes a Boeing 747-400 for the simulations and offers a realistic experience to users in terms of flight management. Users can simulate flights all around the world utilizing the global navigation database of Aerowinx. Users can input data into the FMS and Mode Control Panel (MCP) amongst a range of other control inputs available to pilots. Aerowinx also allows users to adjust and simulate different flight settings such as system malfunctions and aircraft loading parameters along with different environmental conditions such as winds and weather phenomenon. The analysis tool in Aerowinx allows users to simulate a flight and record second-by-second flight data similar to a flight data recorder (FDR). The flight data can be downloaded as a Microsoft Excel file which allows researchers to conduct statistical tests and analysis on the simulated flight data. The researchers set the simulation as per the objectives and methodology required for the 20 simulated flights and utilized the analysis functions for the analysis in this study.

\section{Flight Planning}

The flight planning utilized the NavBlue Flight Planning software. The researchers utilized the cost index settings preset on the Navblue program and utilized the most efficient route calculated by the software as per the settings selected by the researcher (Group A and Group B flights). Every flight was planned with an alternate that was within a distance of 100 nautical miles from the destination airport. Every flight was operated at the same cruise altitude of FL340 (except flights A1 and B1 in Table 1). The Boeing 747-400 utilized for the simulation and had a capacity of 400 passengers. The research planned each flight with 350 passengers and 2000 pounds of additional cargo. 10 different city pairs were chosen by the researcher for the 20 simulated flights (10 flights in Group A and 10 flights in Group B). Every departure and arrival airport utilized for the simulated flights was part of the 29 core airports selected by the FAA for PBN implementation. The researcher selected the core airports because the core airports have the highest availability of PBN procedures which helped build a credible comparative analysis between Group A and Group B flights. The 10 citypairs were chosen by considering the great circle route (GCR) distance between the departure and arrival airport to ensure that the researcher simulated flights of varying distances to study the impact of PBN on different flight times and distances. Table 1. describes the 20 simulated flights that were conducted for this study. The shortest flight had a GCR of 470 nautical miles while the longest flight had a GCR of 4189 nautical miles as the researcher aimed to gather data from flights of varying routes distances and times. 


\section{Table 1}

Details of the 20 Simulated Flights

\begin{tabular}{|c|c|c|c|}
\hline Group A & Group B & Flight & $\begin{array}{l}\text { Great Circle } \\
\text { Distance }\end{array}$ \\
\hline Flight A1 & Flight B1 & $\begin{array}{c}\text { New York-John F } \\
\text { Kennedy Airport } \\
\text { (KJFK) to } \\
\text { Charlotte/Douglas } \\
\text { International Airport } \\
\text { (KCLT) }\end{array}$ & $\begin{array}{l}470 \text { Nautical } \\
\text { Miles }\end{array}$ \\
\hline Flight A2 & Flight B2 & $\begin{array}{l}\text { New York-John F } \\
\text { Kennedy Airport } \\
\text { (KJFK) to } \\
\text { Minneapolis-St Paul } \\
\text { International Airport } \\
\text { (KMSP) }\end{array}$ & $\begin{array}{c}894 \text { Nautical } \\
\text { Miles }\end{array}$ \\
\hline Flight A3 & Flight B3 & $\begin{array}{c}\text { New York-John F } \\
\text { Kennedy Airport } \\
\text { (KJFK) to Denver } \\
\text { International Airport } \\
\text { (KDEN) }\end{array}$ & $\begin{array}{l}1413 \text { Nautical } \\
\text { Miles }\end{array}$ \\
\hline Flight A4 & Flight B4 & $\begin{array}{c}\text { New York-John F } \\
\text { Kennedy Airport } \\
\text { (KJFK) to Seattle } \\
\text { Tacoma } \\
\text { International Airport } \\
\text { (KSEA) }\end{array}$ & $\begin{array}{l}2104 \text { Nautical } \\
\text { Miles }\end{array}$ \\
\hline Flight A5 & Flight B5 & $\begin{array}{c}\text { New York-John F } \\
\text { Kennedy Airport } \\
\text { (KJFK) TO Los } \\
\text { Angeles } \\
\text { International Airport } \\
\text { (KLAX) }\end{array}$ & $\begin{array}{c}2151 \text { Nautical } \\
\text { Miles }\end{array}$ \\
\hline
\end{tabular}




\begin{tabular}{|c|c|c|c|}
\hline Flight A6 & Flight B6 & $\begin{array}{c}\text { Seattle Tacoma } \\
\text { International Airport } \\
\text { (KSEA) to Miami } \\
\text { International Airport } \\
\text { (KMIA) }\end{array}$ & $\begin{array}{l}2367 \text { Nautical } \\
\text { Miles }\end{array}$ \\
\hline Flight A7 & Flight B7 & $\begin{array}{c}\text { Dallas Fort Worth } \\
\text { International Airport } \\
\text { (KDFW) to Daniel } \\
\text { K Inouye } \\
\text { International Airport } \\
\text { (PHNL) }\end{array}$ & $\begin{array}{l}3228 \text { Nautical } \\
\text { Miles }\end{array}$ \\
\hline Flight A8 & Flight B8 & $\begin{array}{l}\text { Minneapolis-St Paul } \\
\text { International Airport } \\
\text { (KMSP) to Daniel K } \\
\text { Inouye International } \\
\text { Airport (PHNL) }\end{array}$ & $\begin{array}{l}3451 \text { Nautical } \\
\text { Miles }\end{array}$ \\
\hline Flight A9 & Flight B9 & $\begin{array}{l}\text { Atlanta Hartsfield- } \\
\quad \text { Jackson } \\
\text { International Airport } \\
\text { (KATL) to Daniel K } \\
\text { Inouye International } \\
\text { Airport (PHNL) }\end{array}$ & $\begin{array}{l}3912 \text { Nautical } \\
\text { Miles }\end{array}$ \\
\hline Flight A10 & Flight B10 & $\begin{array}{c}\text { Washington Dulles } \\
\text { International Airport } \\
\text { (KIAD) to Daniel K } \\
\text { Inouye International } \\
\text { Airport (PHNL) }\end{array}$ & $\begin{array}{c}4186 \text { Nautical } \\
\text { Miles }\end{array}$ \\
\hline
\end{tabular}

\section{Route Distance}

\section{Results}

The route distance in this analysis includes the distance the aircraft traveled from take-off at the departure airport to landing at the arrival airport. The distance covered by the aircraft during taxi was not considered for the analysis. The data for flight distance for Group A and flight distance for Group B was gathered from Aerowinx. Figure 3 depicts the GCR, route distance for Group A, and route distance for Group B. 


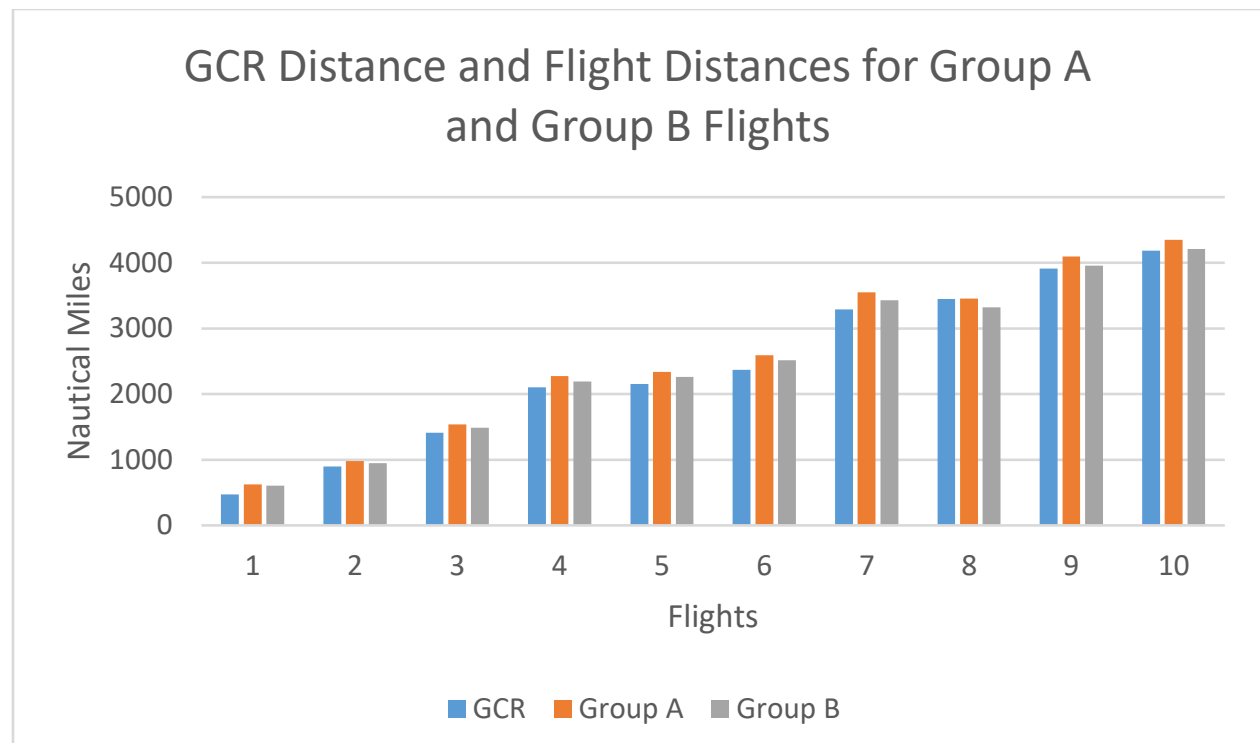

Figure 3. GCR, flight distance for Group A, and flight distances for Group B.

As depicted in Figure 3, the flights in Group A had higher flight distances than the flights in Group B. The average increase in flight distance was 3.47\%. As depicted in figure 4, the percentage difference between group A flights and group B flights remained largely constant with an increase in GCR distance. However, the absolute difference (Nautical Miles) increases with an increase in GCR distance.

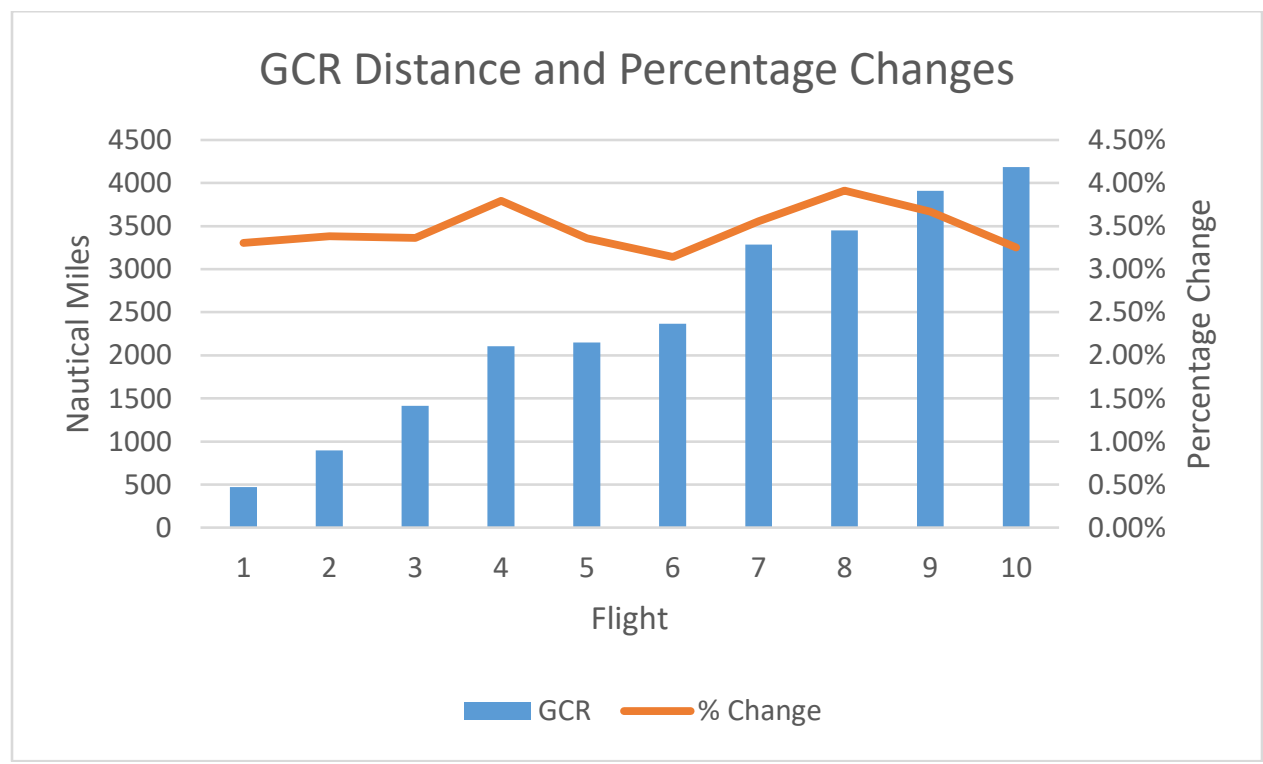

Figure 4. Percentage change in flight distances with GCR. 


\section{Flight Time}

The flight times calculated in this analysis include the time from take-off at the departure airport to landing at the arrival airport. Taxi times at the departure and arrival airports were not included in the analysis. Figure 5 depicts the flight times for group A and group B flights.

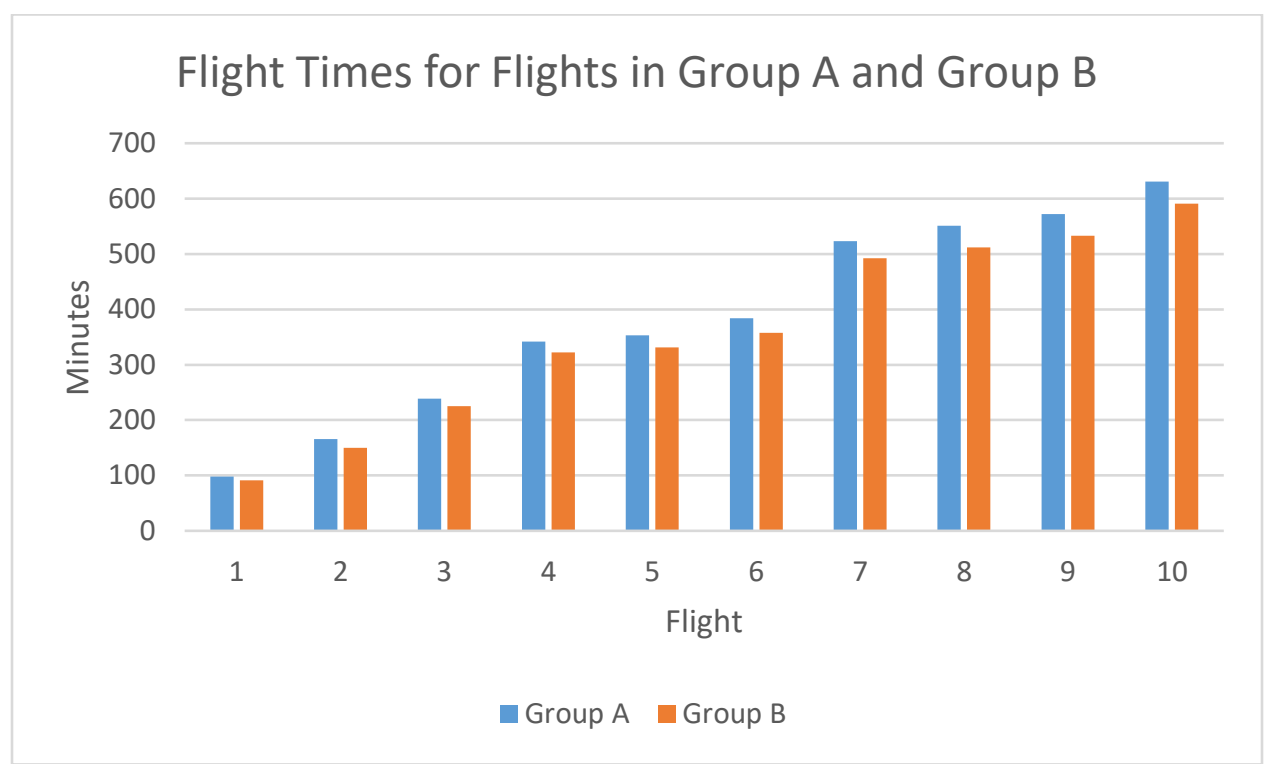

Figure 5. Flight times (minutes) for flights in Group A and Group B.

As depicted in figure 5, the flights in Group A had higher flight times than the flights in Group B. The average increase in flight times was 7.277\%. Figure 6 depicts the percentage change in flight times for flights with increasing GCR distance. 


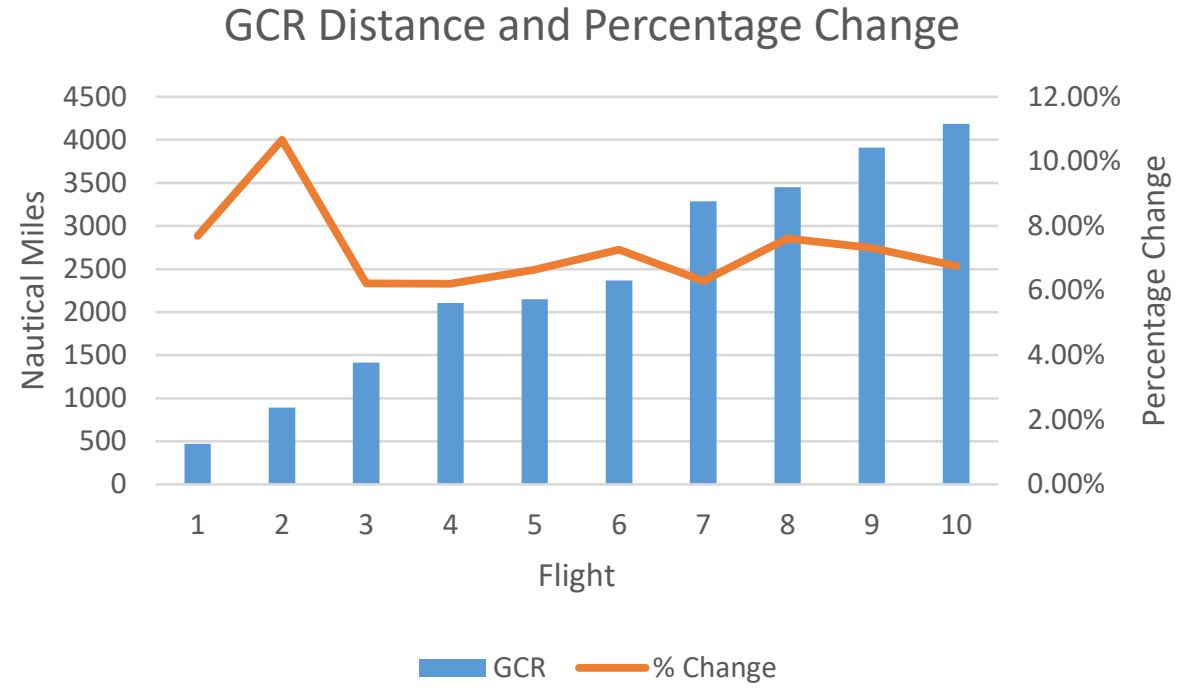

Figure 6. Percentage increase in flight times between Group A and Group B with GCR distance (NM).

\section{Flight Fuel Usage}

For this analysis, the fuel usage was analyzed from the time the aircraft took off at the departure airport to the time the aircraft landed at the arriving airport. The fuel usage during taxi was not considered in the analysis. Figure 7 depicts the difference in fuel usage for the flights in Group A and flights in Group B.

Flight Fuel Usage for Flights in Group A and Group B

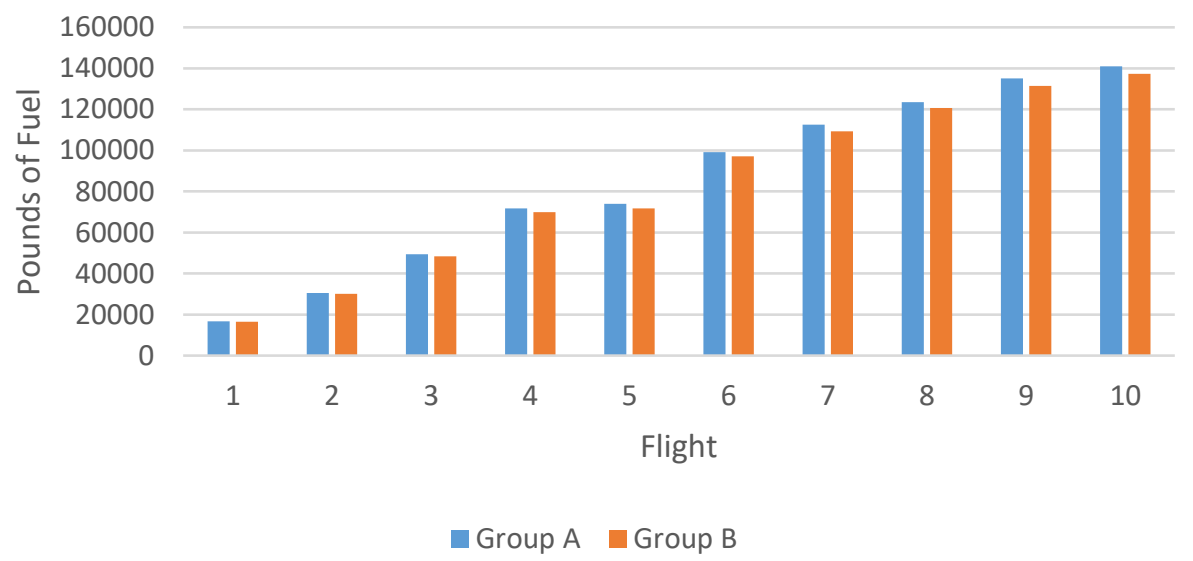

Figure 7. Fuel usage for flights in Group A and Group B. 
As depicted in figure 7, the flights in Group A had higher fuel usage than the flights in Group B. The average increase in fuel usage was $2.34 \%$. Figure 8 depicts the percentage change in flight times for flights with increasing GCR distance.

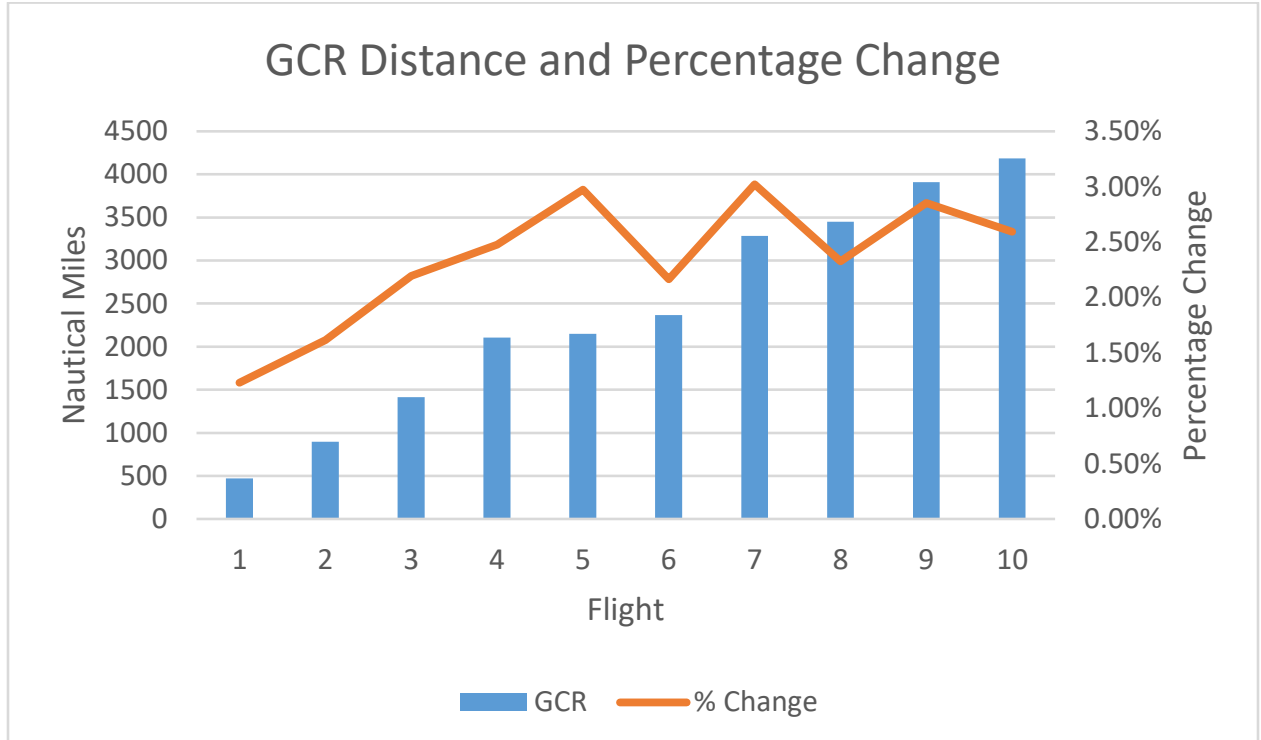

Figure 8. Percentage increase in fuel usage between Group A and Group B with GCR distance (NM).

\section{Analysis by Flight Segment}

For the purpose of this study, the flights were segmented into departure, en-route, and en route segments. The fuel usage and time to climb were analyzed for each segment for every simulated flight.

\section{Departure segment}

For this analysis, the departure segment of a flight is considered the segment of a flight when an aircraft takes-off from the departure airport and climbs to the cruise altitude. The data recorded from Aerowinx was filtered to only analyze data in the departure segment. Figure 9 depicts the time taken by the flights of Group A and Group B during the departure segment. The average increase in time (departure segment) for Group A compared to time for Group B was $14.93 \%$. The time differences between Group A and Group B do not significantly change with an increase in GCR distance as all flights utilized a common flight altitude of FL340 (except flights A1 and B1 in Table 1)(Figure 9). 


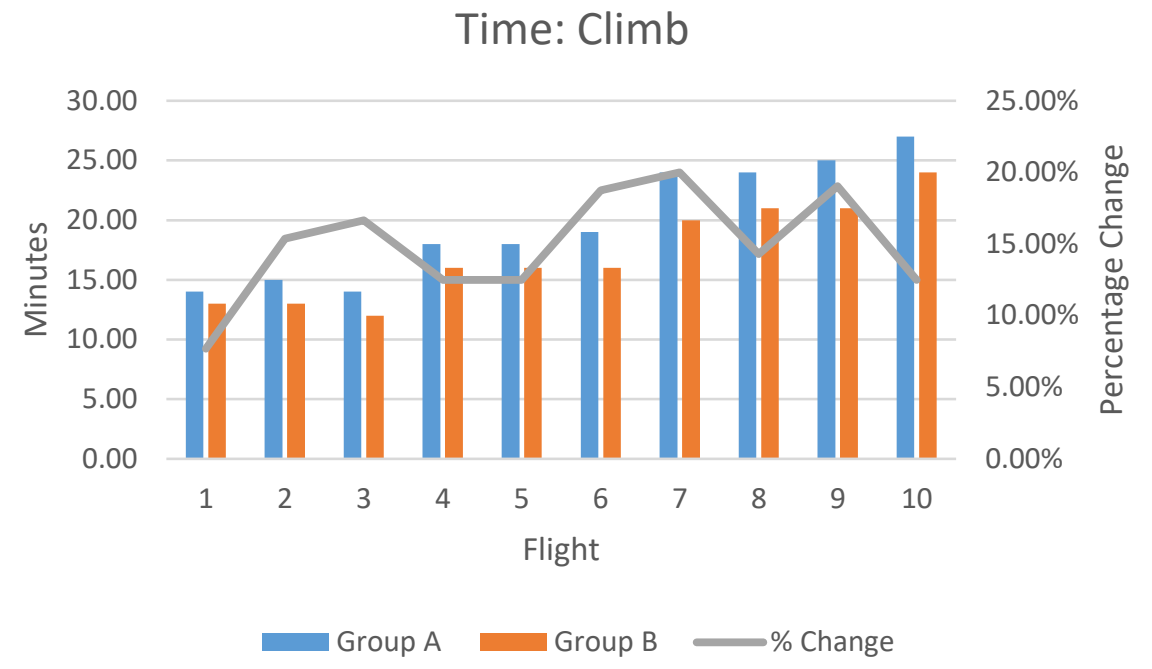

Figure 9. Time is taken to climb to cruise altitude for flights in Group A and Group B.

Figure 10 depicts the fuel used by the flights of Group A and Group B during the departure segment. The average increase in fuel usage (departure segment) for Group A compared to time for Group B was $2.46 \%$. The percentage change in fuel usage for Group A and Group B remains largely constant with an increase in route distance.

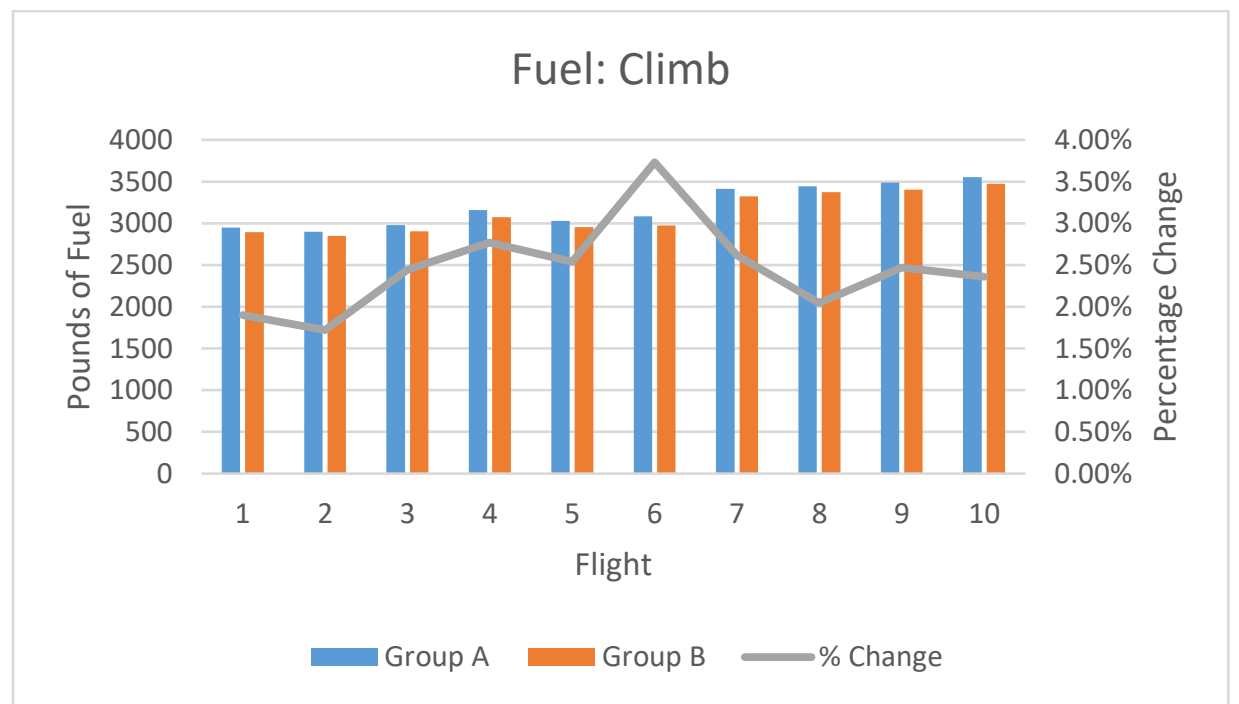

Figure 10. Fuel usage for departure to cruise altitude for flights in Group A and Group B. 


\section{En route segment}

For the purpose of this analysis, the en-route segment of flight will be considered the segment of the flight when the aircraft reaches the cruise altitude to the point when the aircraft commences descent to the arrival airport. Figure 11 depicts the time taken by the flights of Group A and Group B during the en route segment. The average increase in time (en route segment) for Group A compared to time for Group B was $11.84 \%$. The time in the en route segment for Group A is significantly higher than time in the en route segment for Group B.

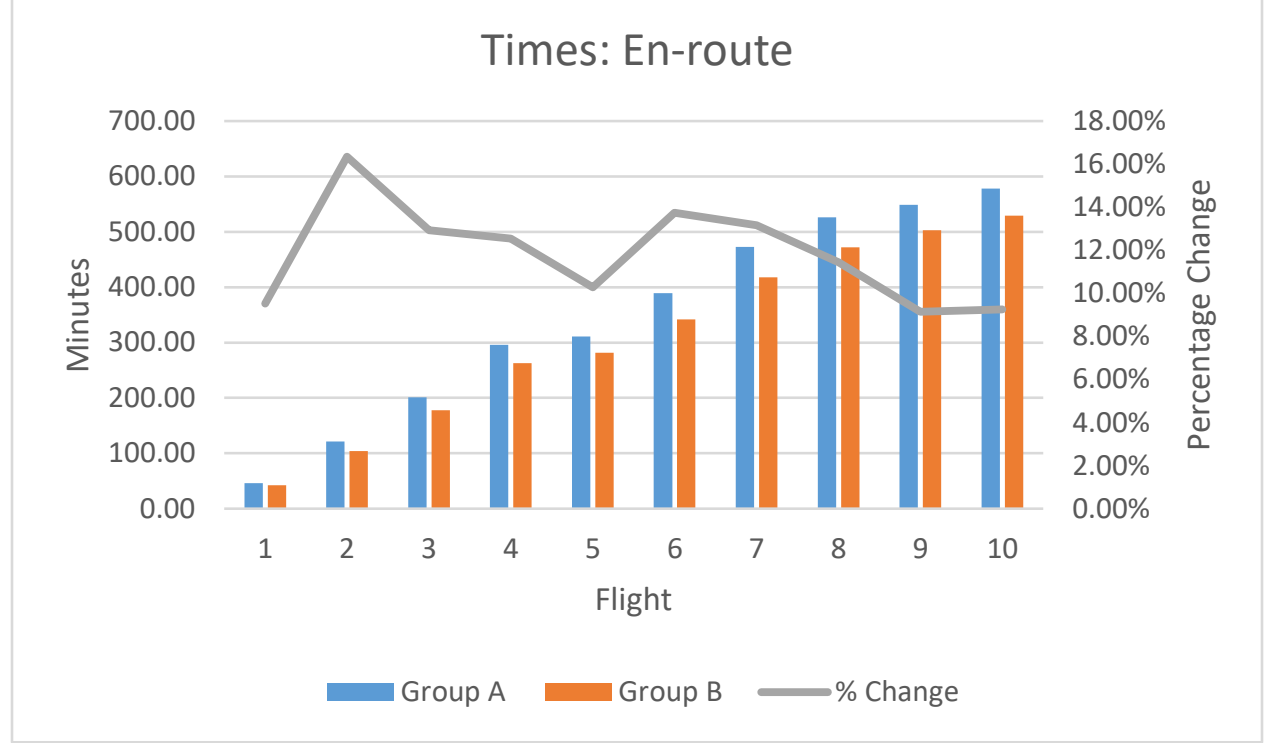

Figure 11. Time of flight in the en route segment.

Figure 12 depicts the fuel usage by the flights of Group A and Group B during the en route segment. The average increase in fuel usage (en route segment) for Group A compared to time for Group B was $2.93 \%$. The fuel usage in the en route segment for Group A is significantly higher than the fuel usage for Group B. 


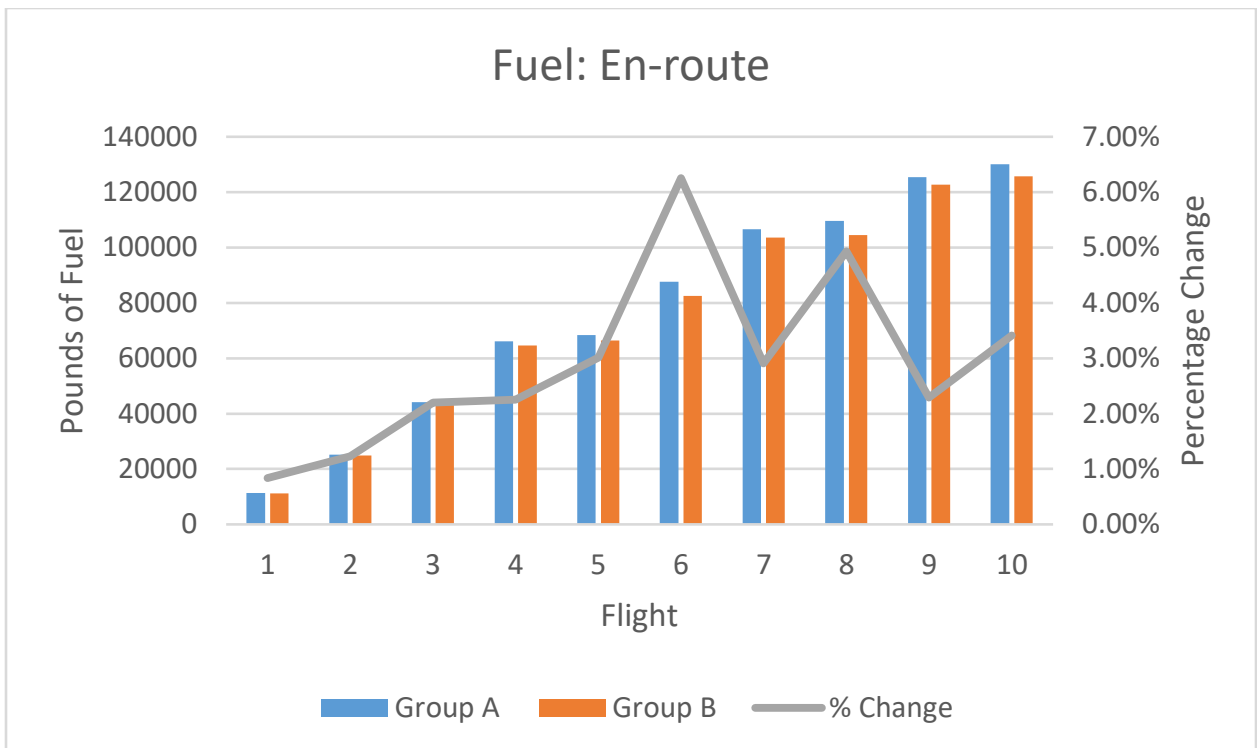

Figure 12. Fuel usage for flights in the en route segment.

\section{Arrival segment}

For the purpose of this analysis, the arrival segment of a flight will be considered the segment of the flight when the aircraft begins the descent from the en route segment to the arrival airport. Figure 13 depicts the time taken by the flights of Group A and Group B during the arrival segment. The average increase in time (arrival segment) for Group A compared to time for Group B was $10.47 \%$. The percentage change in time for Group A and Group B remains largely constant with an increase in route distance. 


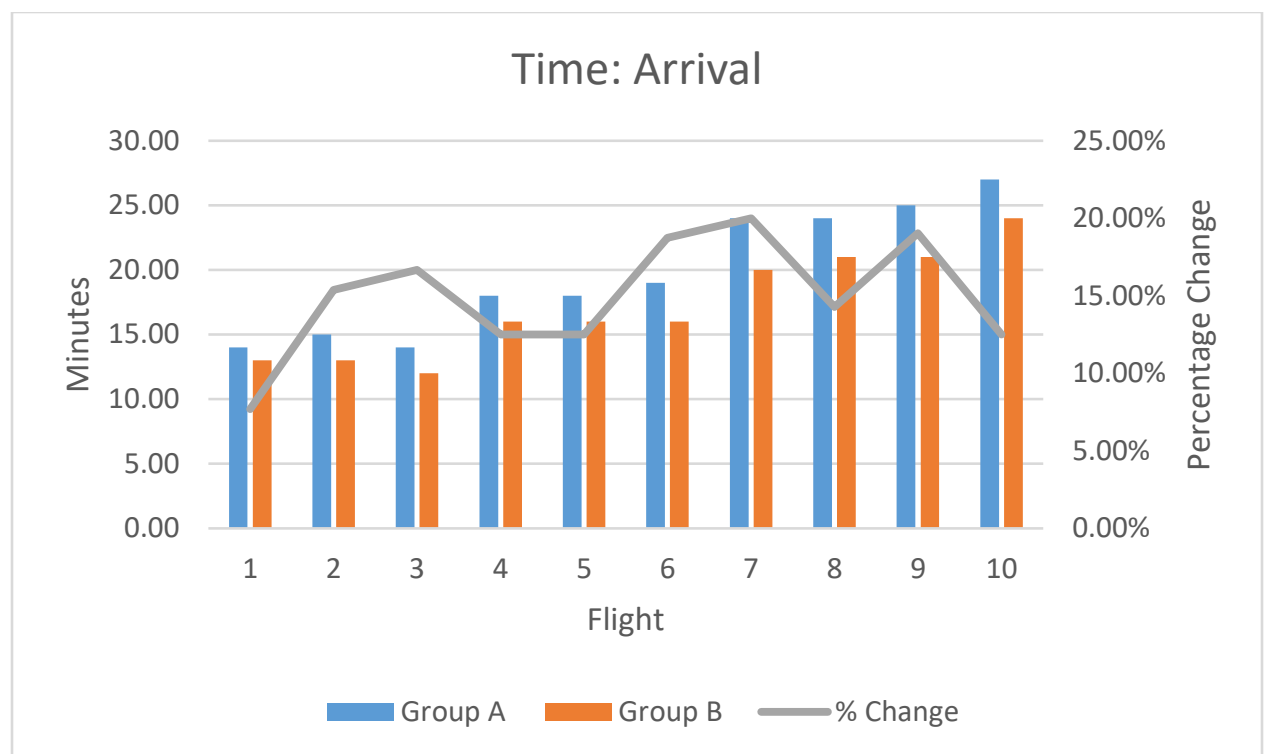

Figure 13. Flight times during the arrival segment.

Figure 14 depicts the fuel usage by the flights of Group A and Group B during the arrival segment. The average increase in fuel usage (arrival segment) for Group A compared to time for Group B was 2.48\%. The percentage change in fuel usage for Group A and Group B remains largely constant with an increase in route distance.

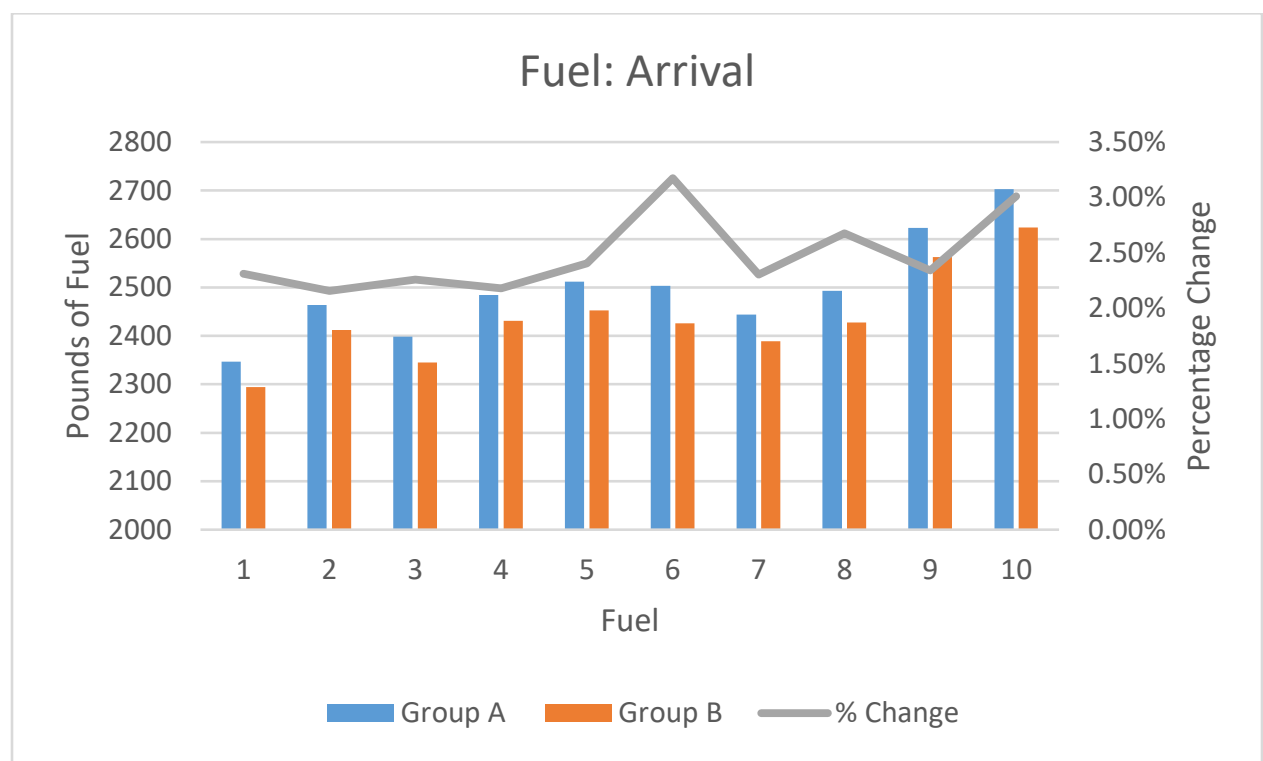

Figure 14. Fuel usage during the arrival segment. 


\section{Discussion}

The purpose of this study was to analyze the effects of PBN on fuel and block time efficiency. As reviewed in the literature, fuel and block times can affect the efficiency and profitability of an airline. The FAA explained that the introduction of PBN will allow aircraft to fly more optimized routes and fly more efficient procedures into and out of airports in the terminal airspace. In this study, 20 flights on a Boeing 747-400 were simulated for 10 different city-pairs. The analysis function of the Aerowinx Precision Simulator was utilized to derive the results of this study.

In terms of the route distance from the origin airport to the destination airport, the route distances for Group A and Group B flights were larger than the GCR distance for all 10 city-pairs. Although a large focus in the development of $\mathrm{PBN}$ has been to increase the availability of direct routes, it is an operationally complex to develop routes that are almost the same distances as the GCR distance. However, the results indicate that utilizing newer GPS routes allow aircraft to fly shorter routes. The average decrease in route distance for Group B flights in comparison to Group A flights was 3.47\%. Additionally, the results indicated that with an increase in route distance, the absolute difference in distance (nautical miles per route) increased which indicates an increased advantage for utilizing advanced PBN routes and procedures on longer routes. This decrease in route distance resulted in a decrease in flight times and fuel usage for Group B flights in comparison to Group A flights. The simulations utilized for this study do indicate increased fuel savings of approximately $2.34 \%$ for utilizing advanced PBN procedures. These savings will not only result in increased profitability margins for the airlines but also decrease fuel emissions. While $2.34 \%$ might only result in limited fuel savings for operators with small scale operations, larger operators/airlines can substantially reduce fuel usage if PBN procedures are utilized on the entire fleet. Additionally, the fuel saved per route (Pounds of fuel saved per trip) increased with an increase in route distance. So while utilizing PBN procedures might bring limited benefits for airlines flying shorter regional routes, airlines operating aircraft on long haul routes will gain significant advantages in terms of fuel savings. The results of the percentage fuel savings from this study can be utilized for an enhanced cost-benefit analysis by comparing the average cost savings due to lower fuel usage and the cost of equipping and maintaining the aircraft fleet to comply with $\mathrm{PBN}$ regulations. A cost-benefit analysis for an operator should consider factors such as fleet type, average route distance for the operator, type of airports operated (core vs non-core airports), and the cost of maintenance.

The simulation utilized for this study also indicated an increase in time savings with an increase in route distance. While the time savings were observed to be marginal for shorter routes (3-10 minutes), the time savings can be 
significantly larger for long haul routes (>20 minutes). Saving of more than 20 minutes per flight can significantly increase block time efficiency for an airline when considering large scale operations. Increased block time efficiency allows for increased utilization of each aircraft which can lead to increased profits. As observed in the results for time savings, the benefits offered for shorter routes are limited and there is a need for a cost-benefit analysis for smaller operators operating flights on shorter routes. This cost-benefit analysis needs to consider factors such as aircraft fleet, cost of maintaining and equipping aircraft to comply with PBN regulations, types of airports operated (core vs non-core airports), and average route distance for the operator. The cost-benefit analysis can be a foundation for future research.

The results were also divided in terms of time and fuel usage for the climb, en-route, and en route segments. The largest savings in fuel and time were observed in the en route segment which is because an aircraft spends the most time in a flight during the en route segment and is most likely to gain the largest benefits (minutes and pounds of fuel saved). In comparison to Group A flight, Group B had higher fuel savings (mean savings of 2.46\%) and time savings (mean savings of $14.93 \%$ ) during the en route segment. While the percentage changes in terms of fuel and time savings were largely constant with an increase in route distance, the absolute values of fuel and time increased significantly offering increased benefits in long haul routes in comparison to short-haul routes. It is critical to consider that for longer routes, the fuel-on-board the aircraft during the take-off segment was larger than the fuel-on-board for shorter routes which resulted in an increase in the take-off weights of the aircraft. An increase in the weight of the aircraft will not only lead to degraded performance but also lead to increased fuel usage. This needs to be factored in while analyzing the results of the fuel and time savings during the departure segment. For the arrival segment, the fuel and time savings remained marginal with an increase in route distance for Group A and Group B. Irrespective of the route distance, flights are approximately near at the same weight and fuel remaining during the arrival segment which results in largely equal performance irrespective of route distances. However, the marginal time and fuel savings can lead to increased time and fuel savings for large operators when these marginal savings are multiplied for the entire fleet. In comparison to Group A flight, Group B had higher fuel savings (mean savings of $2.48 \%$ ) and time savings (mean savings of $10.47 \%$ ) during the en route segment. While the percentage changes in terms of fuel and time savings were largely constant with an increase in route distance, the absolute values of fuel and time increased significantly offered increased benefits in long haul routes in comparison to short-haul routes.

The results in this study provide a more comprehensive perspective when considered for an operator with large scale operations. Fuel savings of $2.48 \%$ 
might not be significant for a single flight but can lead to significant profit margins for an airline that operates more than 1,000 flights a day. Similarly, a saving of 10-20 minutes might seem insignificant when considering a single flight but can lead to increased efficiency, higher fleet utilization, and the possibility of an additional flight per day for an aircraft when the results are multiplied for the entire fleet of a large operator.

\section{Conclusion}

The purpose of this study was to analyze the effects of PBN on fuel and block time efficiency. While the results of this study have multiple limitations, the study provides a literature foundation for future studies to study the economic feasibility and cost-benefit analysis for the benefits offered by PBN for operators with different route distances and types of operations. Utilizing advanced PBN routes and procedures had a direct impact on fuel and block time efficiency for the simulated flights. While the percentage changes in terms of fuel and time savings were largely constant with an increase in route distance, the absolute values of fuel and time increased significantly offering increased benefits in long haul routes in comparison to short-haul routes. These benefits were observed because, with an increase in PBN capability, the flights were flown on shorter routes and utilized more efficient departure and arrival procedures. Operators operating on long haul routes with larger operations will benefit in terms of fuel expenditure and time savings by investing in equipping and maintaining the aircraft to comply with higher PBN capability requirements. For an airline, this benefit will not only result in decreased fuel expenditure but also will allow airlines to adjust block times that will help airlines in disruption management, reduce delays, optimize operational procedures such as cost index, and increase aircraft utilization. This study analyzed the benefits offered by PBN to operators and the benefits offered with PBN are expected to improve as we move towards the Charlie and Delta segments of the PBN implementation plan. With the Charlie and Delta segment of the PBN implementation to be completed by 2030, the users of the NAS will benefit from the economic and operational advantages offered by PBN.

\section{Limitations}

The study has several limitations and it is critical to be aware of the limitations before interpreting the results of this study. All the data utilized for this study was gathered from a simulator for a Boeing 747-400. The operational parameters analyzed in this study might vary when the same study might be conducted in an actual aircraft. Additionally, only 10 city-pairs with 20 simulations were analyzed. A study analyzing FDR data from a larger sample set with repeated flights in the same city-pair will offer data that can be more easily generalized. All the city-pairs were restricted to the US and airports that were 
categorized as core airports by the FAA. While the results of this study have multiple limitations, the study provides a literature foundation for future studies to study the economic feasibility and cost-benefit analysis for the benefits offered by PBN for operators with different route distances and types of operations. 


\section{References}

Aerowinx. (2020). Introduction. Aerowinx Precision Flight Simulator. http://www.aerowinx.com/

Eagan, M. E., \& Gundry, R. (2018). Airport noise and performance-based navigation: A force for good or evil? Journal of Airport Management, 12(4), 359-369. https://www.ingentaconnect.com/ content/hsp/cam/2018/00000012/00000004/art00005

Fan, T. (2019). Schedule creep - In search of an uncongested baseline block time by examining scheduled flight block times worldwide 1986-2016.

Transportation Research Part A: Policy and Practice. https://doi.org/10.1016/j.tra.2019.01.006

Federal Aviation Administration. (2016a). Approval guidance for RNP operations and barometric vertical navigation in the U.S National Airspace System and in oceanic and remote continental airspace. Advisory Circular 90105A. https://www.faa.gov/documentLibrary/media/Advisory_Circular /AC_90-105A.pdf

Federal Aviation Administration. (2016b). PBN NAS navigation strategy 2016. U.S Department of Transportation. https://www.faa.gov/nextgen/ media/PBN_NAS_NAV.pdf

Federal Aviation Administration (2018). NextGen implementation plan 2018-19. Office of NextGen. https://www.faa.gov/nextgen/media/ NextGen_Implementation_Plan-2018-19.pdf

Federal Aviation Administration. (2020a). Aeronautical information manual 2020. Washington, DC: Author.

Federal Aviation Administration. (2020b). Modernization of U.S. airspace. United States Department of Transportation. https://www.faa.gov/nextgen/

Federal Aviation Administration. (2020c). Performance reporting: Details. United States Department of Transportation. https://www.faa.gov/nextgen/ reporting/details/

Ferguson, J., Kara, A., Hoffman, K., \& Sherry, L. (2013). Estimating domestic US airline cost of delay based on the European model. Transportation Research Part C. Emerging Technologies. https://doi.org/10.1016/j.trc.2011.10.003।

International Civil Aviation Organization. (2008). Performance-based navigation (PBN) manual: Doc 9613. https://www.icao.int/SAM/Documents/2009/ SAMIG3/PBN\%20Manual\%20-\%20Doc\%209613\%20Final\%205\% 2010\%2008\%20with\%20bookmarks1.pdf

Kang, L., \& Hansen, M. (2018). Assessing the impact of tactical airport surface operations on airline schedule block time setting. Transportation Research Part C. Emerging Technologies, 89, 133-147. https://doi.org/10.1016/j.trc.2018.01.018 
Kasim, K. (2017). Assessing the benefits of performance-based navigation procedures. Journal of Aviation Technology and Engineering, 7(1), 45-49. https://doi.org/10.7771/2159-6670.1145

Maria, L., Vaaben, B., \& Barnhart, C. (2017). Integrated disruption management and flight planning to trade off delays and fuel burn. Transportation Science, 51, 1, 88-111. https://doi.org/10.1287/trsc.2015.0609

Nakmura, D., \& Royce, W. (2008). Operational benefits of performance-based navigation. Boeing Aero Magazine. https://www.boeing.com/commercial/ aeromagazine/articles/qtr_2_08/AERO_Q208_article3.pdf

Navblue. (2020). N-flight planning. Navblue: An Airbus company. https://www.navblue.aero/product/n-flight-planning/

Sohoni, M., Lee, Y., \& Klabjan, D. (2011). Robust airline scheduling under block time uncertainty. Transportation Science, 45(4), 451-464. http://doi.org/10.1287/trsc.1100.0361

Tian, Y., Wan, L., Chen, C., \& Yang, Y. (2015). Safety assessment method performance-based navigation airspace planning. Journal of Traffic and Transportation Engineering. https://doi.org/10.1016/j.jtte.2015.08.005

U.S Department of Transportation. (2020). Airlines and Airports: Traffic. Bureau of Transportation Statistics. https://www.transtats.bts.gov /Data_Elements.aspx?Data=2 